\title{
Uma proposta didática para ensinar os conceitos de reação de saponificação na edução de jovens e adultos
}

\section{A didactic proposal to teach the saponification reaction concepts in youth and adult education}

Profa. Dra. Maria da Conceição de Menezes Torres

Universidade Estadual da Paraíba - UEPB

Centro de Ciências e Tecnologia - CCT

Departamento de Química - DQ

\section{RESUMO}

A presente pesquisa teve como objetivo elaborar e aplicar uma proposta didática para abordar os conceitos de reação de saponificação, tendo como base o tema gerador "descarte consciente de óleo vegetal". A proposta didática teve um enfoque Ciência, Tecnologia, Sociedade e Ambiente (CTSA), visto que buscou-se abordar um tema voltado para poluição do meio ambiente provocado pelo descarte inadequado de óleo vegetal de frituras. A pesquisa realizada foi um estudo de caso realizado em uma Escola estadual de Campina Grande - PB. O público-alvo foram estudantes do ciclo VI da Educação de Jovens e Adultos (EJA). A proposta didática foi dividida em etapas, que consistiu na avaliação do perfil da turma, problematização inicial, organização do conhecimento e experimentação. O instrumento de coleta de dados foram três questionários, para avaliar o perfil da turma, uma sondagem a respeito dos conhecimentos prévios dos alunos e verificação da proposta didática aplicada. Como resultado foi possível analisar uma turma composta igualitariamente por jovens e adultos, que na sua maioria tem afinidade pela Química. Porém, esses alunos apresentaram pouco conhecimento acerca do conteúdo abordado devido as limitações de conteúdos vistos anteriormente. Contudo, ao decorrer das etapas foi possível observar o desenvolvimento dos mesmos a partir do envolvimento durante as aulas teórica e experimental. Os questionários aplicados no início e no fim das etapas foram analisados e concluiu-se que a grande maioria conseguiu aprimorar seus conhecimentos satisfatoriamente.

Palavras-Chave: Educação de Jovens e Adultos. Ensino de Química Orgânica. Reação saponificação. Experimentação.

\section{ABSTRACT}

The present research aimed to develop and apply a didactic proposal to address the concepts of saponification reaction, based on the generating theme "conscious disposal of vegetable oil". The didactic proposal had a Science, Technology, Society and Environment (STEM) approach, since it aimed to address an issue 
related to environmental pollution caused by improper disposal of vegetable frying oil. The research was a case study carried out in a state school in Campina Grande - PB. The target audience were students from cycle VI of the Young and Adult Education (EJA). The didactic proposal was divided into stages, which consisted of the evaluation of the class profile, initial problematization, knowledge organization and experimentation. The data collection instrument was three questionnaires, to evaluate the class profile, a survey of the students' previous knowledge, and verification of the didactic proposal applied. As a result, it was possible to analyze a class composed equally of young people and adults, most of whom have an affinity for chemistry. However, these students had little knowledge about the content addressed due to limitations of content previously seen. However, during the stages it was possible to observe their development from their involvement during the theoretical and experimental classes. The questionnaires applied at the beginning and at the end of the stages were analyzed and it was concluded that most of them managed to improve their knowledge satisfactorily.

Key-Words: Youth and Adult Education. Organic Chemistry Teaching. Saponification reaction. Experimentation.

\section{INTRODUÇÃO}

Nos dias atuais a busca pela capacitação e conhecimento vem sendo disputada pelos cidadãos, a fim de se adequarem as exigências do novo século. Com isso nota-se a importância da educação no processo de crescimento intelectual dos indivíduos.

Dentre as diversas modalidades de ensino, destaca-se a Educação de Jovens e Adultos (EJA), que é destinada àqueles que não tiveram acesso ou continuidade de estudos no Ensino Fundamental e Médio na idade própria e constituirá instrumento para a educação e a aprendizagem ao longo da vida (Brasil, 1996).

Aspectos sociais, econômicos e culturais apresentados pelos discentes da EJA podem estar relacionados a desistência desses alunos de estudar, dentre esses fatores é comum encontrar alunos que desistiram dos estudos para trabalhar, ou porque constituiu uma família e até mesmo pela própria falta de estímulo do indivíduo pela educação. Assim, surge a necessidade de atribuir práticas metodológicas ao ensino, com o objetivo de estimular esses alunos, tornando-os sujeitos ativos e motivados durante as aulas (Rosa, Silva e Galvan. 2013). 
O ensino de Química tem como função propiciar os alunos a tomarem decisões no seu contexto social, de modo que os conteúdos abordados em sala de aula não façam dos alunos apenas ouvintes, mas que os instigue a pô-los em prática no seu cotidiano. Para isso, é necessário que o professor se posicione de forma crítica e problematizadora, trazendo abordagens que contribua para que os alunos construam seus conhecimentos a partir de suas experiências.

Nesse sentido, Vidal e Melo (2013) chama atenção para a questão da contextualização, de modo que esta não seja uma mera citação de exemplos de eventos do cotidiano e sim um vínculo desses eventos com o conhecimento científico, a fim de facilitar a aprendizagem e atrair o aprendiz as reflexões sobre o determinado conteúdo estudado. Sendo assim, o aluno poderá assumir a posição de sujeito ativo a partir das discussões em sala de aula, onde o mesmo é capaz de pensar, formular teoria e se sentir bem na escola e fora dela e, consequentemente, isso pode resultar no surgimento do interesse do aluno pelo conhecimento.

A contextualização pode ser abordada na sala de aula a partir de temas geradores, que envolve situações problemas presentes no cotidiano das pessoas ou no meio social em que elas estão inseridas. Uma forma de se trabalhar com temas geradores é abordando uma problemática que tenham um enfoque CTSA - Ciência, Tecnologia, Sociedade e Ambiente, visto que este enfoque traz questionamentos a respeito de problemas ambientais, bem como discussões sobre a natureza do conhecimento científico e seu papel na sociedade.

O presente estudo se faz de grande importância no meio educacional, uma vez que propõe utilizar métodos de intervenção baseados no cotidiano dos alunos e com o auxílio das práticas experimentais, na finalidade de considerar as necessidades existentes nos alunos da modalidade EJA, de modo que possa tornar o conteúdo de química orgânica mais interessantes e menos complicado na visão desses discentes, visando uma aprendizagem significativa. Nessa perspectiva, pensou-se em abordar um assunto que tivesse enfoque CTSA (Ciência, Tecnologia, Sociedade e Ambiente), visando um ensino contextualizado, o qual possa instigar os alunos a refletirem melhor as questões ambientais que os cercam. Desta forma, o tema gerador escolhido foi "descarte consciente de óleo vegetal", onde foi possível abordar os conceitos da Reação de Saponificação 
numa abordagem CTSA. A escolha do tema foi feita a partir da análise do perfil dos alunos, de modo que buscou-se abordar algo que pudesse envolver toda a turma, bem como, respeitou-se os conteúdos abordados na disciplina de Química. Visto que, a turma era do ciclo $\mathrm{VI}$ (correspondente ao $3^{\circ}$ ano do ensino regular) e os assuntos abordados são relacionados a química orgânica.

\section{ENSINO DE QUÍMICA PARA EDUCAÇÃO DE JOVENS E ADULTOS}

A função do ensino de química é desenvolver a capacidade de tomada de decisão e para que isso ocorra é necessário que haja uma vinculação do conteúdo trabalhado com o contexto social em que o aluno está inserido. Desta forma, surge a necessidade do professor abordar a problematização na sala de aula, de modo que haja a construção de conhecimentos acerca das experiências vividas pelos alunos (Delizoicov, Angotti e Permanbuco, 2018).

A disciplina de Química deve superar o ensino tradicional, de modo que proporcione aos alunos a construção de uma visão de mundo mais articulada e menos fragmentada, a fim de que os mesmos possam ter autonomia no exercício da cidadania, contribuindo para que o indivíduo se veja como participante de um mundo em constante transformação (Brasil, 1999).

Os Parâmetros Curriculares Nacionais para o Ensino Médio (PCNEM) propõe que a disciplina de química seja ministrada a partir de uma abordagem contextualizada, de forma que aborde temas associados ao cotidiano dos alunos, relacionando os mesmos com as práticas de ensino, de modo que haja uma aprendizagem significativa dos conteúdos ministrados (Brasil, 2006).

Quando se fala de contextualização Vidal e Melo (2013), chama atenção para a questão de que ambas não é uma mera citação de exemplos de eventos do cotidiano e sim um vínculo desses eventos com o conhecimento científico, a fim de facilitar a aprendizagem e atrair o aprendiz as reflexões sobre o conteúdo estudado. Sendo assim, o aluno poderá assumir a posição de sujeito ativo a partir das discussões em sala de aula, onde o mesmo seja capaz de pensar, formular teoria e se sentir bem na escola e fora dela, portanto, isso pode resultar no surgimento do interesse do aluno pelo conhecimento.

Formar um cidadão alfabetizado cientificamente, de modo que o educando se aproprie dos conhecimentos das Ciências para a compreensão do seu meio 
ambiente e dos fenômenos que estão em sua volta, não é uma tarefa fácil. Cabe aos educadores propiciar aos cidadãos uma alfabetização científica na perspectiva da inclusão social, de modo que o educando possa realizar suas atividades cotidianas, mas consciente sobre os impactos provocados na natureza, se por exemplo, houver um descarte de pilha inadequado, ou até mesmo os danos provocados a saúde por exposição a substâncias tóxicas (Budel, 2016).

Na perspectiva de Santos, Rodrigues Filho e Amauro (2016) para que o ensino de química possa ser cumprido com êxito na EJA, é necessário entender as particularidades, as necessidades, as dificuldades e, principalmente, os diferenciais positivos dos alunos, ou seja, o educador deve abordar os assuntos de modo que haja uma contextualização com o cotidiano do aluno e também com suas ambições futuras. Visto que, a EJA é uma modalidade de ensino que possui caráter político de inclusão, atendendo a uma clientela de alunos que foram privados da escolarização no ensino regular. E o que traz essa parcela de alunos de volta à escola, após tempos de afastamento desse ambiente, é a inserção, ou uma melhor colocação no mercado de trabalho (Andrade et al., 2016).

\section{REAÇÃO DE SAPONIFICAÇÃO NUMA PERSPECTIVA CTSA}

De acordo com os PCNEM (Brasil, 2000), contextualizar o conteúdo significa assumir que todo conhecimento envolve uma relação entre sujeito e objeto. Portanto, a contextualização é um caminho que visa relacionar áreas do conhecimento e dimensões presentes na vida do educando proporcionando uma maior oportunidade de aprendizagem (Budel, 2016). Desta forma é necessário que o professor saiba utilizar a contextualização, para que possa fazer uma conexão entre os acontecimentos do cotidiano com o conhecimento científico, de modo que possa atrair os alunos para reflexões acerca do conteúdo abordado e de fato ocorra uma aprendizagem significativa proposta pelos parâmetros curriculares.

Uma forma de trazer a contextualização para a sala de aula é através de temas geradores, o qual consiste num método de ensino Freiriano que visa abordagem de temas que abrange situações voltadas para a realidade do educador e educando. Esses temas não devem ser apenas aprendidos, mas 
devem trazer reflexões para os alunos, despertando nos mesmos um espírito crítico (Freire, 2009).

Um ensino que envolve os temas geradores, percorre as seguintes etapas: inicialmente a pesquisa dos temas, que consiste no momento de leitura dos assuntos voltados para o cotidiano dos indivíduos; portanto ao captar essas informações e apresenta-las aos educandos ocorre o momento de abstração, ou seja, uma etapa em que se dialoga sobre o tema escolhido, fazendo uma leitura codificada do tema abordado; e por fim o processo de descodificação, que consiste numa reflexão crítica a respeito do tema, indo além dos limites aparentes das situações estudadas, propiciando ao indivíduo uma desconstrução de uma visão ingênua e uma construção de uma visão crítica (Freire, 2009).

A Química orgânica é considerada a área da química que trata dos compostos de carbono e está intrinsecamente relacionada com a vida, portanto pode ser abordada a partir de diversos parâmetros presentes no nosso cotidiano. Porém muitos professores ainda têm dificuldades em contextualizar os conteúdos dessa disciplina durante suas aulas (Pazinato et al., 2012). Visto que o ensino da Química orgânica exige muita abstração e raciocínio espacial, pode acarretar numa dificuldade de aprendizagem por parte dos alunos que não tem afinidade pela disciplina de Química. Nessa perspectiva, associar o tema de descarte consciente de óleo vegetal residual de frituras, para abordagem do conteúdo de reação de saponificação, é uma forma de contextualizar o ensino de Química orgânica.

Diante das variações climáticas que o planeta vem sofrendo nos últimos anos, relacionadas aos desgastes do meio ambiente, tais como desmatamento e a emissão de monóxido de carbono na atmosfera, muitos países vêm buscando adotar uma política de desenvolvimento mais sustentável (Freitas, Barata e Moreira Neto, 2010).

Dentre os materiais que representam grandes ameaças ao meio ambiente devido seu alto poder de poluição, estão os óleos residuais de fritura que são descartados pelos ralos das pias em diversos ambientes domésticos e comerciais. Na maioria dos casos, a população não tem conhecimento a respeito dos grandes malefícios trazidos pelo descarte inadequado do óleo, ou seja, muitas vezes que são despejados nos esgotos acabam chegando aos oceanos (Veloso et al., 2012). 
Segundo SABESP (2019), 1 litro de óleo pode contaminar até 25 mil litros de água. Visto que o óleo é uma substância insolúvel em água devido sua capacidade apolar, quando este entra em contato com substâncias polares forma uma mistura heterogênea, portanto, quando o óleo se mistura com a água este fica sob a superfície, neste caso, nos lagos e rios pode gera uma barreira a qual dificultará à entrada de luz, bloqueando a oxigenação da água, causando um desequilíbrio na cadeia alimentícia aquática. Além do contato com o solo, o qual o óleo tem a capacidade de permeabilizar, dificultando o escoamento de água das chuvas.

Diante disto, uma forma de minimizar os impactos ambientais gerados pelos óleos residuais é por meio da reciclagem. Este ciclo reverso irá reaproveitar e reprocessar esses materiais que antes eram considerados resíduos para gerar novos subprodutos (Veloso et al., 2012). Desta forma, a utilização de óleos residuais, para fabricação de sabão se torna uma alternativa sustentável e que pode ser abordada em sala de aula como tema gerador para ensinar o conteúdo de reações orgânicas, mais precisamente na reação de hidrólise de éster em meio básico (reação de saponificação).

Os óleos são substâncias hidrofóbicas, ou seja, insolúveis em água, os quais são formados por ésteres de triacilgliceróis, sendo produtos resultantes da esterificação entre o glicerol e ácidos graxos. Em função desta imiscibilidade e por possuir densidade menor que a água, quando lançados em mananciais, emerge para a superfície (Wildner e Hillig, 2012). Desta forma o óleo pode causar diversos impactos ambientais, desde a contaminação das águas, solo, mortandade de espécies aquáticas, entupimentos de esgotos etc.

O sabão é produzido através da reação de saponificação, conhecida como hidrólise alcalina, a qual utiliza-se um tipo especial de éster, que são os triglicerídeos, na presença de uma base. Na produção de sabão pode-se utilizar matérias-primas de diversas origens. O triglicerídeo, é um o tipo de gordura mais abundante na natureza e pode ser proveniente do sebo de origem animal, dos óleos vegetais ou da mistura de ambos. Estes sofrem hidrólise básica a quente, produzindo sais de álcalis de ácidos carboxílicos de cadeia longa (Solomons, 2018). 
Quimicamente os sabões apresentam fórmula que contém uma cadeia carbônica $\left(R, R_{1}\right.$ e $R_{2}$ ) variando de doze a dezoito átomos de carbonos, sendo sua característica estrutural de maior importância uma extremidade polar (cabeça) e outra apolar (cauda). Em solução aquosa, o sabão forma miscelas, com a cabeça polar na superfície e a cauda apolar no interior.

Procedimentos METODOLOGIcos

\subsection{NATUREZA DA PESQUISA}

Esta pesquisa se constitui em um estudo de caso, com uma perspectiva qualitativa de cunho descritivo. Segundo Gil (2010), um estudo de caso tem como objetivo explorar situações da vida real, descrever a situação do contexto em que está sendo feita determinada investigação e formular hipóteses. Em relação as pesquisas descritivas, o referido autor afirma ter como objetivo primordial a descrição das características de relações entre as variáveis.

\subsection{PÚBLICO-ALVO DA PESQUISA}

A realização do trabalho envolveu 25 alunos pertencentes ao ciclo $\mathrm{VI}$ da EJA, de uma escola pública localizada na cidade de Campina Grande - PB, a qual atende alunos do próprio bairro, bem como de bairros vizinhos, por ser considerada uma escola referência.

\subsection{PROPOSTA DIDÁTICA PARA O ENSINO DO CONTEÚDO DE REAÇÃO DE SAPONIFICAÇÃO NA EJA.}

Visto que o enfoque dos parâmetros curriculares é melhorar as aulas de química, trazendo diversas abordagens metodológicas que contribua no processo de construção do conhecimento. É necessário a seleção e a organização de temas, conteúdos e habilidades no processo de ensino e aprendizagem, porém apenas isso não é suficiente, tem que haver um trabalho em conjunto com as diferentes ações didáticas, pedagógicas, culturais e sociais, de modo que envolva atividades desde as mais simples como a disposição física da sala de aula, até as atividades mais complexas, envolvendo toda a comunidade escolar e seus entornos (PCN+, 2002). 
Com embasamento nos parâmetros curriculares, elaborou-se a proposta didática, preparação de sabão a partir de óleo vegetal reciclado, para ensinar o conteúdo de Reação de Saponificação, através de um tema gerador associado ao descarte consciente de óleo vegetal, visando a contextualizado do ensino, a qual possa instigar os alunos a refletirem melhor as questões ambientais que os cercam.

Esta proposta foi aplicada em 5 encontros no mês de novembro e dezembro do ano de 2018. A sequência didática foi dividida em etapas, as quais estão descritas no quadro 1

Quadro 01: Etapas executadas na Proposta Didática "Preparação de sabão a partir de óleo vegetal reciclado"

\begin{tabular}{|c|c|c|}
\hline Cronograma & Atividade desenvolvida & Objetivos \\
\hline $\begin{array}{l}1^{\circ} \text { encontro } \\
(30 \mathrm{~min})\end{array}$ & Aplicação do questionário & $\begin{array}{l}\text { Avaliar o perfil dos alunos e conhecer os } \\
\text { recursos didáticos disponíveis na escola. }\end{array}$ \\
\hline $\begin{array}{l}2^{\circ} \text { encontro } \\
(60 \mathrm{~min})\end{array}$ & $\begin{array}{l}\text { Exposição da proposta e } \\
\text { Exibição de vídeo sobre } \\
\text { possíveis problemas ambientais } \\
\text { ocasionados pelo descarte } \\
\text { inadequado de óleo de cozinha. } \\
\text { * } \\
\text { Aplicação de um questionário } \\
\text { relacionado aos conhecimentos } \\
\text { prévios dos alunos. }\end{array}$ & $\begin{array}{l}\text { Induzir a problematização inicial, de modo } \\
\text { que os alunos pudessem refletir acerca do } \\
\text { tema gerador, se autoquestionando a partir } \\
\text { de algumas questões prévias abordadas } \\
\text { inicialmente; apresentar possíveis impactos } \\
\text { ambientais causados pelo descarte } \\
\text { inadequado do óleo residual de fritura e } \\
\text { demonstrar a importância do presente } \\
\text { estudo na vida e no conhecimento dos } \\
\text { alunos; avaliar conhecimentos prévios dos } \\
\text { alunos sobre o assunto abordado em sala } \\
\text { de aula. }\end{array}$ \\
\hline $\begin{array}{l}3^{\circ} \text { encontro } \\
(90 \mathrm{~min})\end{array}$ & $\begin{array}{l}\text { Aula expositiva e ilustrativa, } \\
\text { utilizando ferramentas como } \\
\text { projetor, para construção dos } \\
\text { conceitos sobre a reação de } \\
\text { saponificação. }\end{array}$ & $\begin{array}{l}\text { Ensinar os conceitos de reação de } \\
\text { saponificação, revisar as funções orgânicas } \\
\text { envolvidas nesta reação. Abordar a química } \\
\text { envolvida no sabão. }\end{array}$ \\
\hline $\begin{array}{l}4^{\circ} \text { encontro } \\
(60 \mathrm{~min})\end{array}$ & $\begin{array}{l}\text { Realização do experimento } \\
\text { demonstrativo-investigativo } \\
\text { sobre a reação de } \\
\text { saponificação, utilizando óleo } \\
\text { de cozinha reciclado e soda } \\
\text { cáustica. }\end{array}$ & 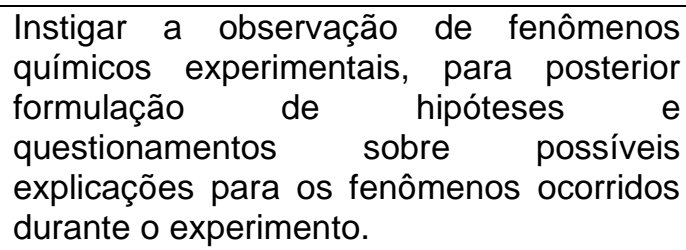 \\
\hline $\begin{array}{l}5^{\circ} \text { encontro } \\
(30 \mathrm{~min})\end{array}$ & $\begin{array}{l}\text { Aplicação de um questionário } \\
\text { final. }\end{array}$ & $\begin{array}{l}\text { Avaliação da proposta de ensino e } \\
\text { aprendizagem. }\end{array}$ \\
\hline
\end{tabular}


"https://www.youtube.com/watch?v=PBdTrot6IEw.

\subsection{INSTRUMENTOS DE COLETA DE DADOS E ANÁLISE DOS RESULTADOS}

$O$ instrumento de coleta de dados utilizado na pesquisa foi um questionário de sondagem com o intuito de identificar o perfil dos alunos da EJA, a estrutura da escola e suas dificuldades na disciplina de química. $E$ dois questionários relacionados ao tema abordado, sendo um aplicado inicialmente para analisar os conhecimentos prévios dos alunos e outro questionário aplicado no final da intervenção para comparar com os resultados iniciais.

\section{DESCRIÇÃO DA ATIVIDADE EXPERIMENTAL}

A atividade experimental ocorreu na quarta etapa da sequência didática e teve como objetivo a realização de uma oficina de produção de sabão, a fim de que os alunos aprendessem como pode ser reaproveitado o óleo de cozinha e pudessem ver na prática as etapas da reação de saponificação.

Para realização do experimento seguiu-se o roteiro, o qual abordava a parte teórica da reação de saponificação, bem como orientava a respeito do procedimento experimental. Durante a realização da prática, foi explicado novamente aos alunos os conceitos mais importantes da reação de saponificação, como a mesma ocorre, bem como a estrutura e as propriedades químicas do sabão.

Os alunos foram instruídos dos cuidados que deveriam ter com os produtos químicos e auxiliaram durante o experimento, além de observarem as etapas do processo. A figura 2 ilustra a interação dos alunos durante a prática experimental.

Figura 2 - Alunos participando da realização do experimento

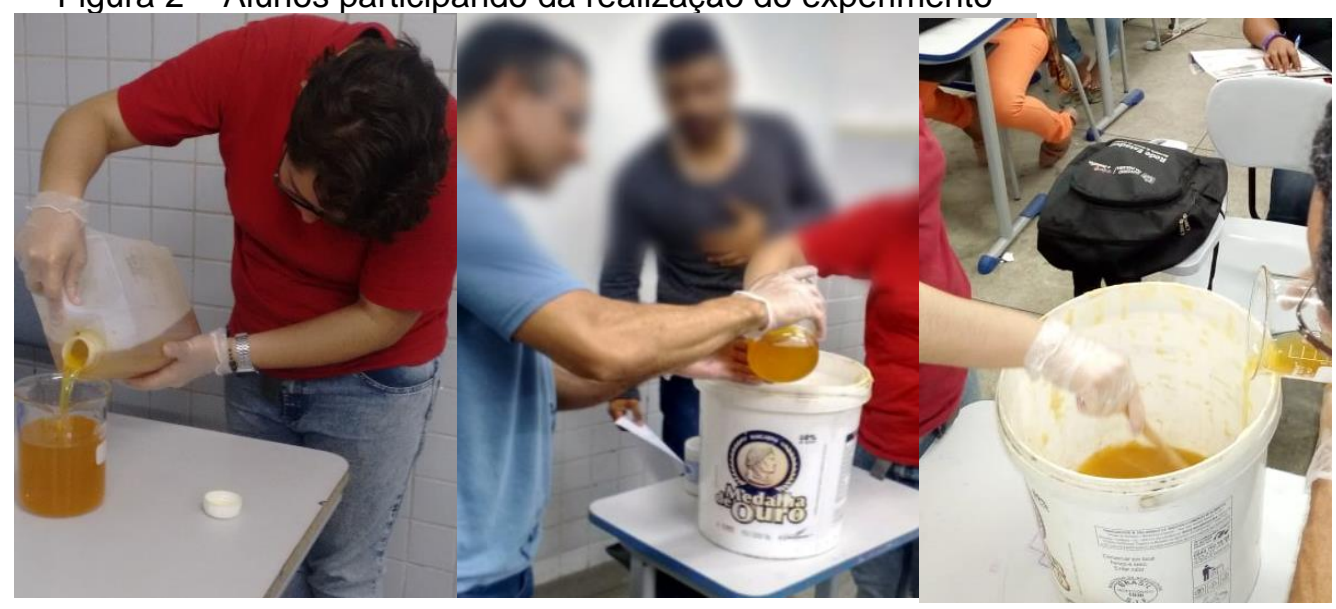


O procedimento experimental para preparação de sabão, foi realizado com óleo de cozinha já utilizado, soda cáustica e água quente. Para produzir o sabão os alunos dissolveram soda cáustica em água quente e, em seguida, adicionaram o óleo vegetal reciclado e mexeram a solução por 40 minutos. Logo após distribuíram o sabão em copos descartáveis para obter o formato desejado e esperou-se uma semana para que pudesse retirá-lo dos recipientes (Figura 3).

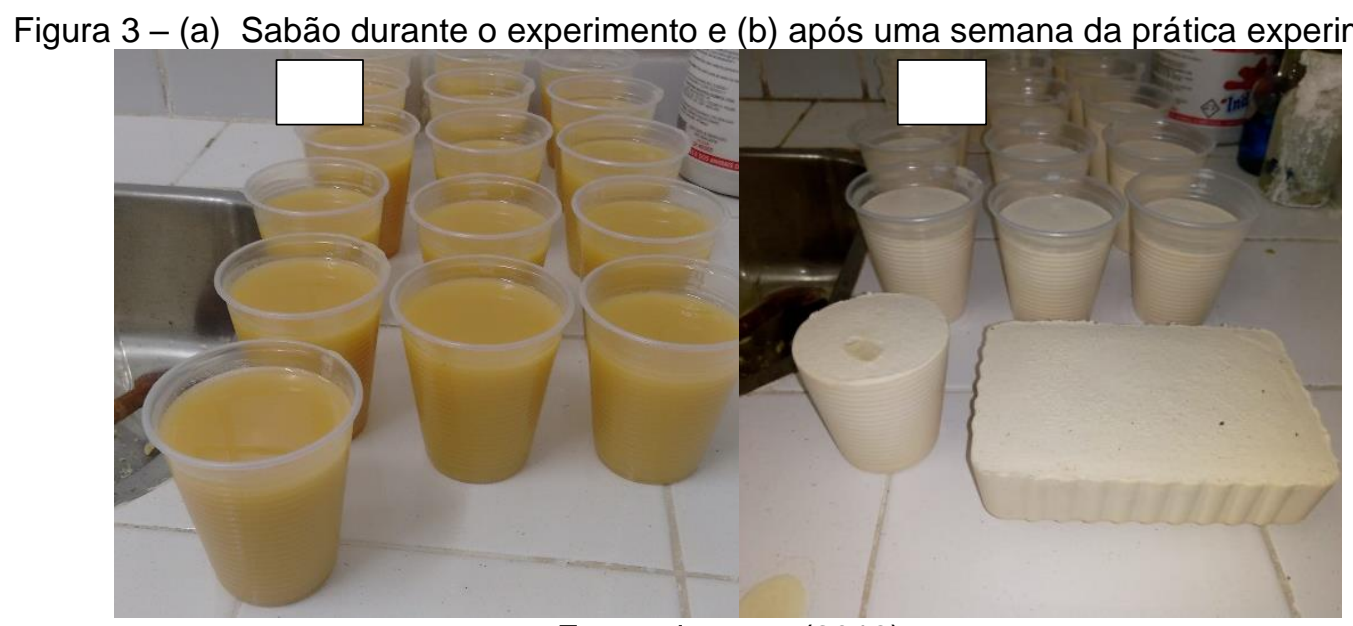

Fonte: do autor (2019)

Durante a prática experimental, os alunos se mostraram curiosos fazendo perguntas e interagindo na fabricação do sabão. Tal comportamento é visto na literatura como um envolvimento vívido, que pode acarretar evoluções no que diz respeito a termos conceituais. Para Francisco Jr e colaboradores (2008) o envolvimento vívido tem como base o pensamento freiriano como a "práxis", que é a ação e reflexão do aluno frente ao desafio que nesse caso é o experimento.

\section{RESULTADOS E DISCUSSÃO}

\subsection{ANÁLISE DO PERFIL DOS DISCENTES DA EJA}

O perfil da turma da EJA pertencentes ao ciclo VI de uma Escola Estadual da cidade de Campina Grande, foi traçado a partir de um questionário que envolveu questões objetivas. Uma vez que, teorias apontam que em uma turma da EJA é possível encontrar uma diversidade de pessoas com idades diferentes, mas com dificuldades de aprendizagem semelhantes. Com isso, o questionário buscou traçar o perfil dos alunos, bem como saber quais recursos didáticos eram 
disponibilizados na escola e utilizados nas aulas de Química, a fim de atender a necessidades dos discentes.

Inicialmente buscou-se saber a faixa etária dos alunos e como ilustrado na Figura 4, a turma possui uma faixa etária mista, onde a maioria dos alunos (29\%) estão na faixa etária de 20 a 25 anos, enquanto a minoria (19\%) encontra-se entre 25 a 30 anos. Na perspectiva de Jardilino e Araújo (2014), as turmas que antes eram formadas exclusivamente por adultos, atualmente, vêm sendo prioritariamente ocupada por jovens que são encaminhados a EJA, geralmente, por alto índice de reprovação no ensino regular.

Figura 4 - Faixa etária dos alunos da EJA

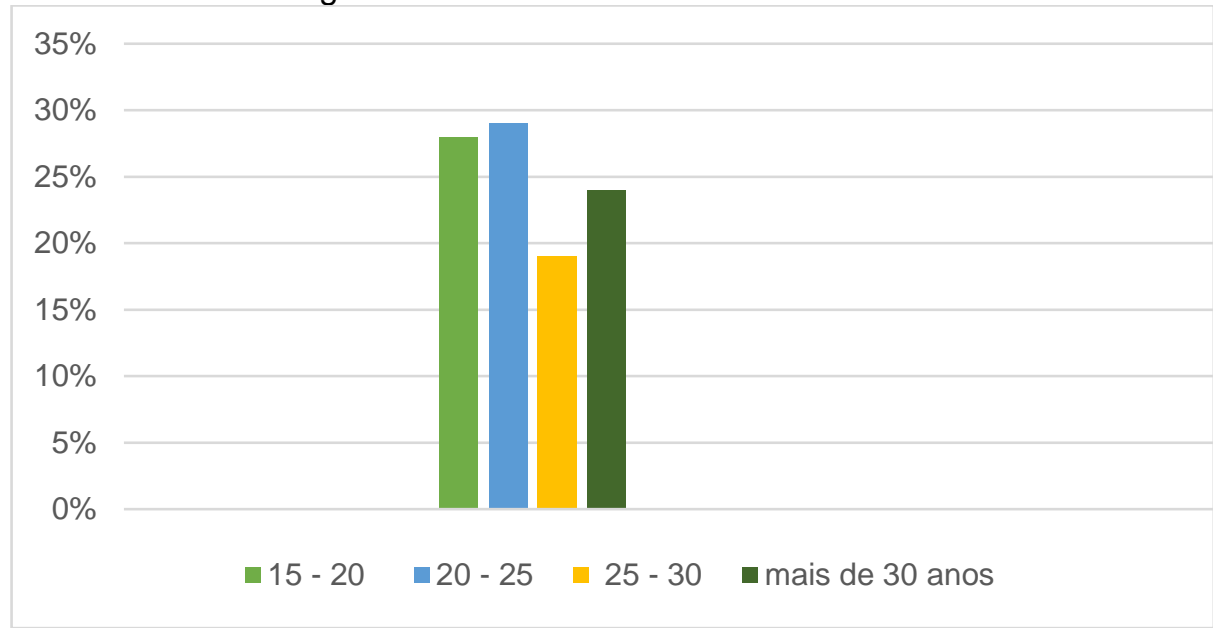

Fonte: do autor (2019)

Os resultados da segunda e terceira questão foram analisados e esboçados na Figura 5. Na segunda questão os alunos foram indagados a respeito de suas dificuldades em relação a disciplina de Química, a maioria (67\%) alegou não ter dificuldades, enquanto 33\% afirmaram ter dificuldade. Na terceira questão buscou-se saber o que os alunos acham a respeito da inclusão da experimentação como contribuinte no processo de ensino aprendizagem. Como observado na Figura 5, 86\% dos alunos afirmaram que a experimentação pode contribuir de forma positiva, enquanto $14 \%$ diz não contribuir para a aprendizagem. De acordo com Pinto (2012), as práticas experimentais podem oportunizar ao aluno o conhecimento da essência da Química, propiciando a compreensão de sua importância e a estreita relação desta Ciência com a natureza que o cerca. Além disso, pode aproximar o elo entre a motivação e 
aprendizagem, de forma que possa acarretar num maior envolvimento por parte dos alunos.

Figura 5 - Análise das dificuldades enfrentadas pelos alunos e a contribuição da experimentação nas aulas.

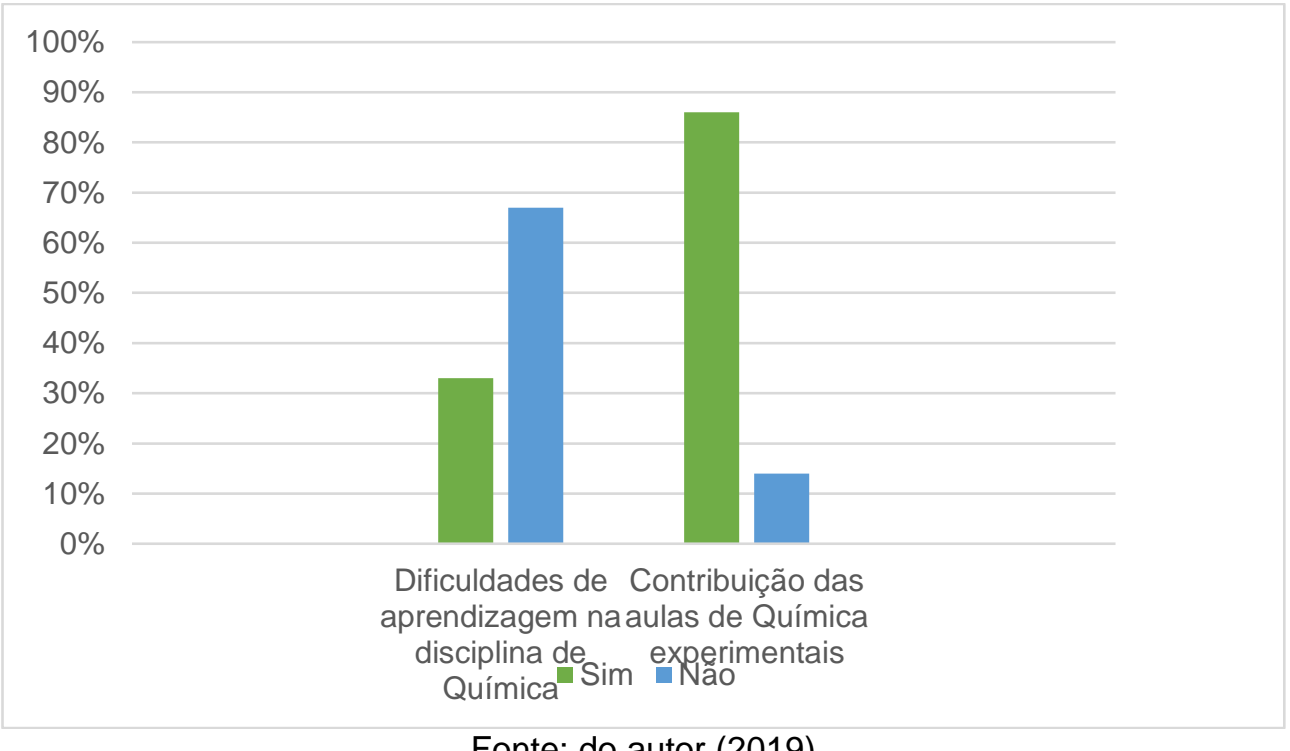

Fonte: do autor (2019)

A análise das aulas de Química na escola, fora feita a partir de perguntas no questionário, que visou saber quais os recursos que o professor de Química utiliza nas suas aulas, bem como saber a opinião dos alunos a respeitos das aulas. Tal análise foi feita, visando inserir possíveis metodologias, as quais os alunos não estão acostumados a presenciar em sala de aula, de forma que essas metodologias sejam efetivas no processo de ensino-aprendizagem.

A quarta questão buscou saber quais são os recursos metodológicos utilizados pelo professor de Química. De acordo com a Figura 6, a maioria dos alunos (90\%) responderam nenhum, enquanto a minoria (10\%) responderam experimento. Levando em consideração a resposta da maioria, percebe-se que o professor não utiliza nenhum recurso didático para auxiliar nas aulas de Química. De acordo com Di Pierro (2008) o professor que não busca metodologias de ensino diferenciadas com a finalidade de melhorar aprendizagem dos alunos, bem como a falta de estrutura adequada na escola, pode contribuir para as dificuldades de aprendizagem, visto que os alunos em muitos casos chegam na sala de aula com problemas, desmotivados e cansados da rotina diária, é necessário que o 
professor desperte o interesse desses alunos. Portanto, os professores devem ter autonomia para optar por metodologias que atenda suas expectativas e às dos alunos, de modo que o ensino de Química se torne efetivo, através de problematização, desafios e estímulos, a fim de que conduza o estudante à construção do saber (Lima, 2012).

Figura 6 - Recursos utilizados nas aulas de Química

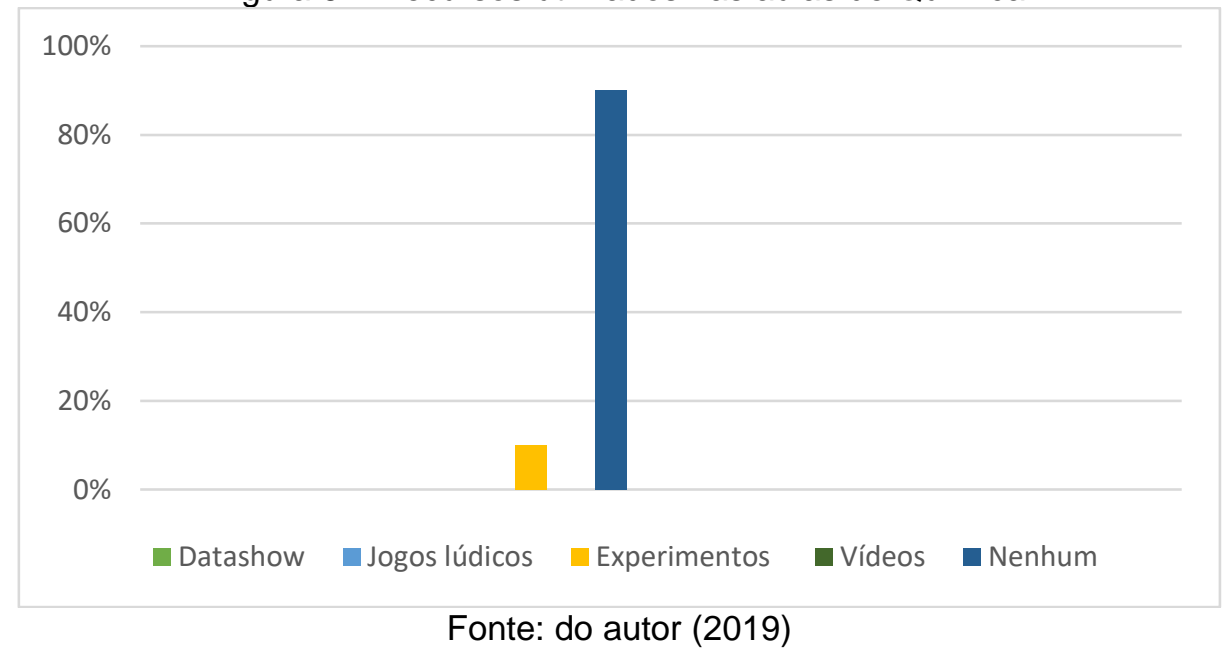

A última questão buscou saber a opinião dos alunos a respeito das aulas de Química na escola. De acordo com a figura 7, a maioria dos alunos $48 \%$ acham boa, seguido de $38 \%$ que acham ótima e apenas $14 \%$ afirmam ser regular, visto isso percebe-se que a maioria dos alunos gostam das aulas de Química.

Figura 7 - Avaliação das aulas de Química na escola

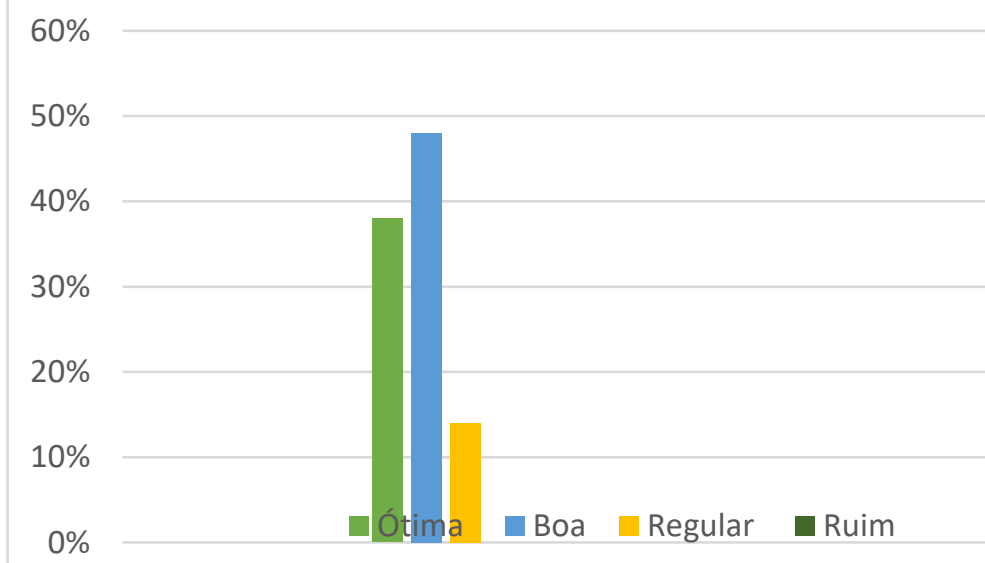

Fonte: do autor (2019) 


\subsection{ANÁLISE DO QUESTIONÁRIO DE SONDAGEM DOS CONHECIMENTOS PRÉVIOS DOS ALUNOS SOBRE O TEMA EM ESTUDO}

A proposta inicial da sequência didática foi avaliar os conhecimentos prévios dos alunos a respeito do tema gerador, para isso utilizou-se um questionário avaliativo, e após sua aplicação, deu-se início as estratégias didáticas para abordagem do conteúdo.

A primeira questão buscou saber quantas vezes ao dia costumava-se utilizar o óleo de cozinha na casa dos alunos, a fim de alerta-los para o descarte adequado do óleo cada vez que usá-lo. Ao analisar as respostas (Figura 8), percebe-se que a maioria (59\%) utiliza três ou mais vezes por dia, enquanto a minoria correspondente a (23\%) e (18\%) utilizam uma ou duas vezes, respectivamente. Estes dados chamam atenção para a importância do processo de conscientização de descarte adequado do óleo, visto que a maioria faz uso frequente do óleo vegetal para fins culinários.

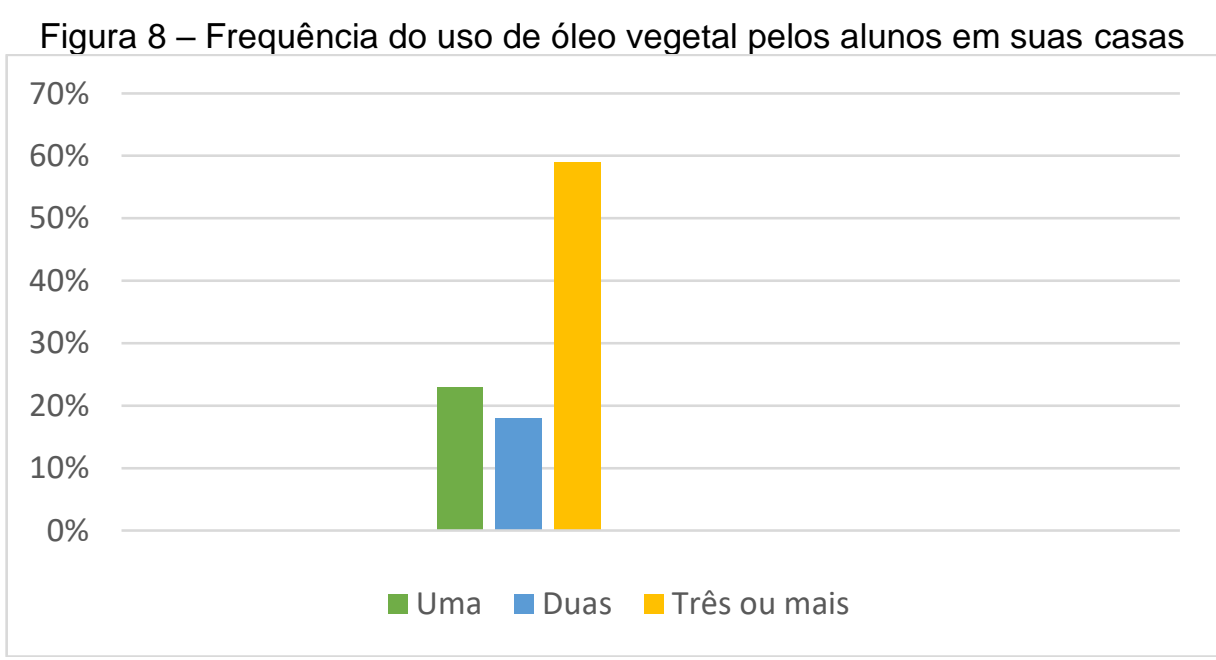

Fonte: do autor (2019)

A segunda questão buscou saber qual o destino que os alunos davam ao óleo que era utilizado em suas casas. As respostas eram semelhantes se dividindo em descartar na pia, no lixo e armazenar para fazer sabão, como mostra a Figura 9. Portanto, a maioria dos alunos (56\%) e (25\%) fazem o descarte inadequado, respondendo que descartam na pia ou no lixo. E, somente, $19 \%$ fazem o descarte adequado armazenando numa garrafa para fornecer a colegas que produzem sabão. Esses resultados são preocupantes para o meio ambiente, uma vez que não há uma disciplina e preocupação das pessoas em preservá-lo, podendo 
contribuir para uma poluição ambiental. Visto que, na perspectiva de Freitas e colaboradores (2010), hoje não existe um modo de descarte ideal para o óleo usado, isto é, mesmo que seja misturado ao lixo orgânico, jogado no ralo, na pia ou na privada, o produto vai custar caro ao meio ambiente. Portanto, quanto mais o cidadão evitar o descarte do óleo no lixo comum, mais contribuirá para a preservação da atmosfera do planeta.

Figura 9 - Destino do óleo na casa dos alunos

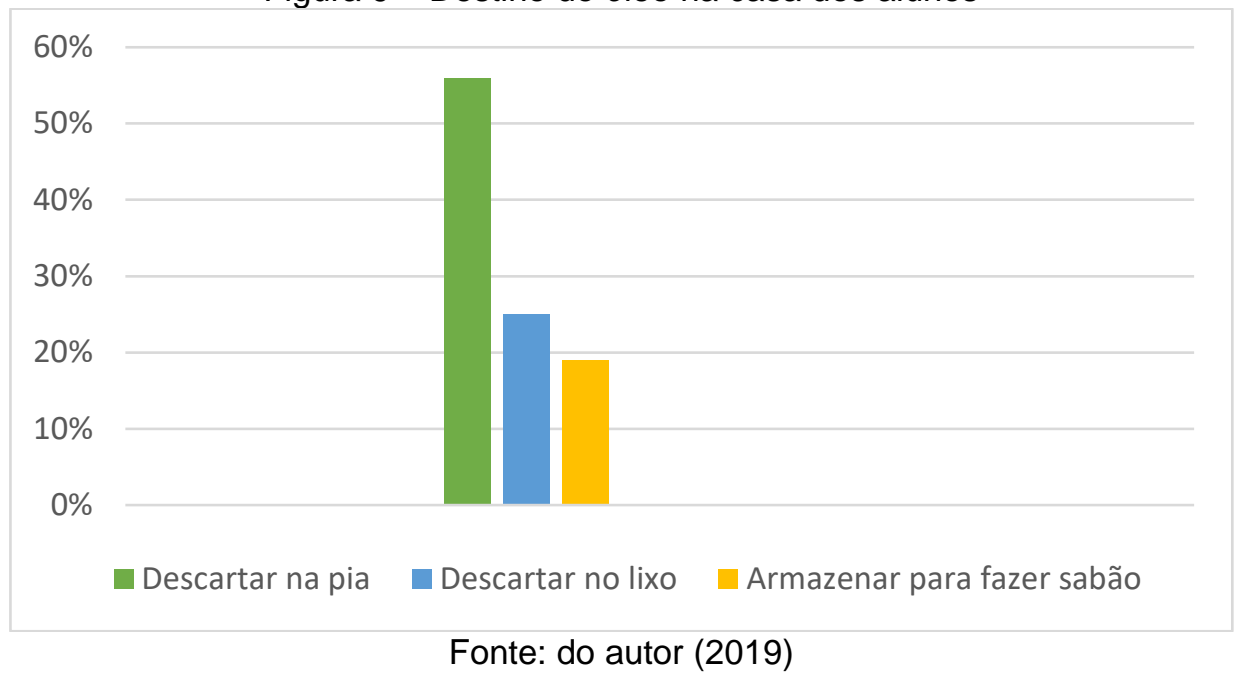

A terceira questão teve o objetivo de analisar a concepção dos alunos a respeito dos impactos que o descarte inadequado de óleo pode trazer ao meio ambiente. Ao observar as respostas percebe-se que todos os alunos têm a concepção de que o descarte inadequado do óleo causa impactos ao meio ambiente, apesar de fazerem o descarte inadequado. Os resultados foram sistematizados no Quadro 2.

Quadro 02 - Sistematização das falas dos alunos participantes da pesquisa, com relação aos impactos do óleo residual de fritura no meio ambiente.

\begin{tabular}{|c|c|c|}
\hline \multicolumn{3}{|c|}{$\begin{array}{l}\text { Categoria 1: Quais os impactos que o descarte inadequado do óleo pode trazer ao meio } \\
\text { ambiente? }\end{array}$} \\
\hline Subcategoria & $\%$ & Fala dos sujeitos \\
\hline $\begin{array}{l}1.1 \text { Os estudantes fazem relação aos } \\
\text { impactos causados na natureza, tais como } \\
\text { a poluição das águas, solo etc. }\end{array}$ & 58 & $\begin{array}{l}\text { "Poluição ao meio ambiente, mares, peixes, } \\
\text { plantas, solo..." (participante 15) } \\
\text { "Causa grandes impactos na natureza." } \\
\text { (participante 7) }\end{array}$ \\
\hline $\begin{array}{l}1.2 \text { Os estudantes fazem relação aos } \\
\text { problemas causados nas residências e } \\
\text { nas ruas, tais como entupimento de pias, } \\
\text { ralos e esgotos. }\end{array}$ & 42 & $\begin{array}{l}\text { "O impacto maior é a poluição do meio } \\
\text { ambiente, o entupimento de pias e ralos } \\
\text { esgotos etc." (participante 6) }\end{array}$ \\
\hline
\end{tabular}


Fonte: do autor (2019)

A quarta questão buscou saber qual a concepção dos alunos sobre o impacto do óleo em contato com a água de rios e mares, se pode ou não ser prejudicial. De acordo com as respostas analisadas 57\% acredita que pode ser prejudicial, causando grandes impactos a fauna e a flora. Enquanto 29\% acredita que o óleo é prejudicial a saúde e por isso pode poluir as águas, já 14\% associou a poluição do óleo nas águas a infertilidade do solo. Os dados foram sistematizados no Quadro 3.

Quadro 03 - Sistematização das falas dos alunos participantes da pesquisa, com relação aos impactos do óleo residual de fritura nas águas.

\begin{tabular}{|l|l|l|}
\hline $\begin{array}{l}\text { Categoria 2: O que acontece com a água dos rios e mares quando entra em contato com o } \\
\text { óleo? Você acha que pode ser prejudicial? Explique. }\end{array}$ \\
\hline $\begin{array}{l}\text { Subcategoria } \\
\begin{array}{l}2.1 \text { Estudantes que relacionam a } \\
\text { poluição do óleo na água com os } \\
\text { impactos causados aos animais e } \\
\text { plantas aquáticos. }\end{array}\end{array} 57 \begin{array}{l}\text { "Os mares e rios, ficam poluídos impossibilitando a } \\
\text { respiração necessária das plantas, peixes etc." } \\
\text { (participante 1) } \\
\text { "Sim, causa impacto nos rios e mares, prejudicando } \\
\text { as águas que ficam poluídas causando mortalidade } \\
\text { dos animais e plantas." (participante 3) }\end{array}$ \\
\hline $\begin{array}{l}2.2 \text { Estudantes que relacionam a } \\
\text { poluição do óleo na água com a saúde } \\
\text { humana. }\end{array}$ & $29 \begin{array}{l}\text { "Pode sim, porque de uma forma o óleo é prejudicial } \\
\text { a saúde." (participante 5) } \\
\text { "Sim, porque prejudica o meio ambiente e até a nossa } \\
\text { respiração porque fica tudo poluído." (participante 13) }\end{array}$ \\
\hline $\begin{array}{l}2.3 \text { Estudantes que relacionam a } \\
\text { poluição do óleo na água com a } \\
\text { infertilidade do solo. }\end{array}$ & 14 & $\begin{array}{l}\text { "Pode provocar infertilidade do solo, matar os } \\
\text { animais do mar, como peixe etc." (participante 12) } \\
\text { "Pode provocar infertilidade no solo." (participante 7) }\end{array}$ \\
\hline
\end{tabular}

Fonte: do autor (2019)

A última questão buscou saber o porquê da utilização do sabão ou detergente para remover as gorduras das panelas e foi solicitado que os alunos explicassem quimicamente o que ocorre. Ao analisar essa questão observou-se que $100 \%$ dos alunos justificaram dizendo que remove facilmente a gordura das panelas, porém nenhum aluno conseguiu explicar quimicamente o que ocorre. Tal resposta era prevista, visto que, eles usaram o senso comum, ou seja, os conhecimentos obtidos pela experiência no cotidiano, porém não souberam responder quimicamente porque não tinham o conhecimento científico a respeito do assunto, como mostra a fala do participante 9. 
"Utilizamos porque é mais fácil para remover a gordura das panelas, pois tem uma composição que faz remover as gorduras mais rápido." (participante 9)

A partir dos resultados analisados no questionário de sondagem juntamente com a primeira etapa proposta na sequência didática, a qual se constitui na problematização inicial, em que foi apresentado imagens e vídeo a respeito do tema gerador, percebe-se que todos os estudantes conseguiram relacionar os fatos do cotidiano com o conteúdo exposto, apesar de alguns alunos conseguirem se expressarem melhor relacionando e justificando a importância do estudo no seu cotidiano. Quando o aluno consegue assimilar as informações fornecidas pelo professor com as informações que fazem parte do seu senso comum, começa a construir conceitos que resultarão numa aprendizagem significativa. Na concepção de Guimarães (2009), esse tipo de aprendizagem ocorre quando uma nova informação está ligada a conceitos preexistentes na estrutura cognitiva do aprendiz, ou seja, quando o aluno consegue assimilar as informações que lhe foram fornecidas com as ideias que já fazem parte do seu conhecimento.

A última etapa da sequência didática consistiu na aplicação de um questionário, a qual tem como objetivo avaliar a concepção dos alunos a respeito da proposta didática aplicada nas aulas de Química, bem como avaliar o seu aprendizado, para isso foi aplicada novamente uma questão que já fora perguntada no questionário de sondagem. Tal momento de acordo com Delizoicov (2014), se baseia na etapa final que consiste na aplicação do conhecimento. Esta etapa se destina a abordar sistematicamente o conhecimento incorporado pelo aluno. Esse conhecimento é mais bem construído quando se analisa e interpreta as situações propostas inicialmente e outras que possam ser explicadas e compreendidas pelo mesmo corpo de conhecimentos.

A primeira questão buscou saber qual a opinião dos alunos a respeito da proposta de ensino aplicada para o conteúdo de reações orgânicas, e os resultados para a metodologia abordada pela professora foram satisfatórios. De acordo com os resultados analisados na Figura 10,60\% da turma declarou ótima, enquanto $40 \%$ afirmou ser boa. Visto que a metodologia didática se diferencia da metodologia tradicional, por envolver tecnologias, contextualizações e experimentação, é previsto uma boa aceitação por parte dos alunos. 
Figura 10 - Opinião dos alunos em relação a metodologia de ensino

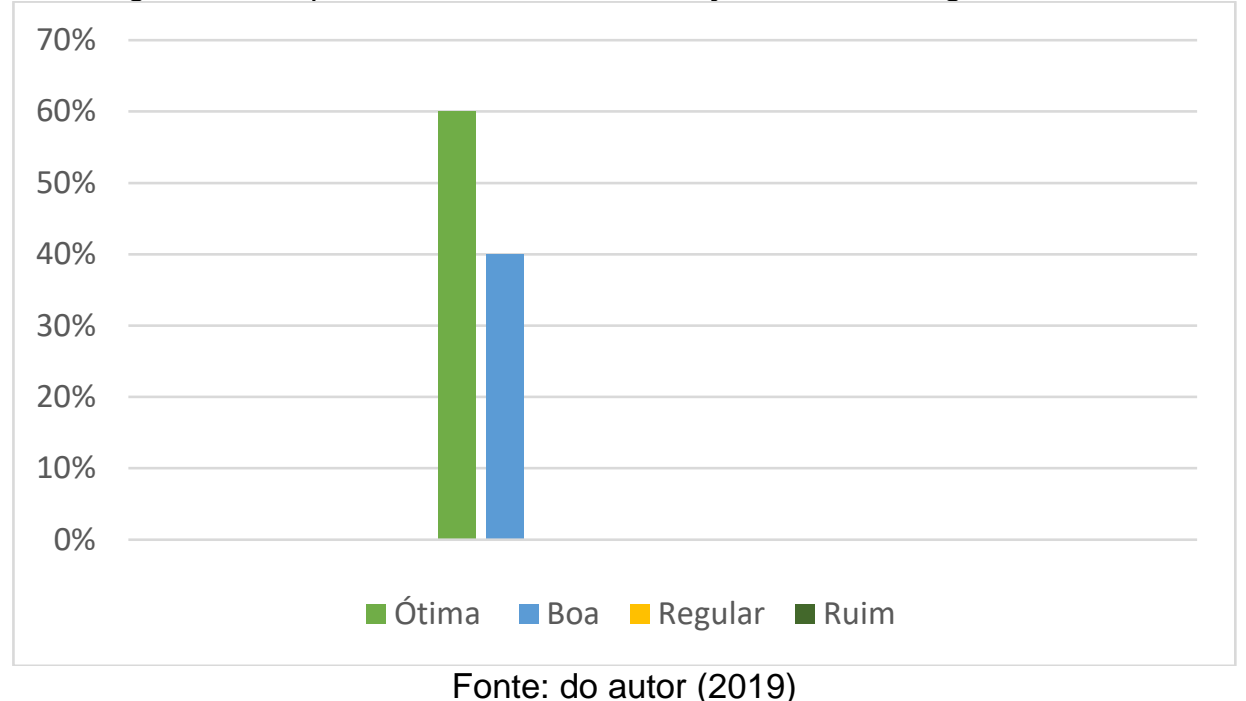

Fonte: do autor (2019)

A segunda questão teve como objetivo compreender se o uso do tema "Descarte consciente de óleo vegetal" contribuiu para aprendizagem do conteúdo de reações de saponificação na concepção dos alunos. De acordo com as respostas analisadas todos os alunos (100\%) afirmaram que contribuiu positivamente para seu aprendizado. Para confirmar essas respostas, foram feitas duas questões subjetivas visando compreender melhor a concepção dos alunos a respeito do conteúdo abordado.

A terceira questão buscou saber se o conteúdo abordado possibilitou os alunos a observarem questões ambientais presentes no seu cotidiano, relacionado ao descarte inadequado de óleo. De acordo com as respostas analisadas, foi possível ver que os alunos compreenderam os riscos da poluição do óleo nas águas, bem como sugeriram o que foi feito na aula experimental, o reaproveitamento do óleo para fabricação de sabão. As respostas foram sistematizadas no Quadro 5. 
Quadro 05 - Sistematização das falas dos alunos participantes da pesquisa, com relação ao aprendizado a respeito dos problemas ambientais provocados pelo óleo residual de fritura.

\begin{tabular}{|l|l|l|}
\hline $\begin{array}{l}\text { Categoria 1: O conteúdo abordado Ihe possibilitou observar questões ambientais presentes } \\
\text { no seu cotidiano relacionado ao descarte inadequado de óleo? Se sim, quais? }\end{array}$ \\
\hline Subcategoria & $\%$ & \begin{tabular}{l} 
Fala dos sujeitos \\
\hline $\begin{array}{l}\text { 1.1 Estudantes que citou os problemas } \\
\text { ambientais causados pelo descarte } \\
\text { inadequado do óleo residual de fritura. }\end{array}$ \\
"Observei que não podemos descartar óleo nas pias, \\
pois entope e causa enchentes, quando os bueiros \\
entopem. Além da grande poluição que o óleo faz na \\
água." (participante 4) \\
"Poluição da água, entupimento da caixa de esgoto, \\
poluição do mar e destruição da natureza." \\
(participante 3)
\end{tabular} \\
\hline $\begin{array}{l}\text { 1.2 Estudantes que falou a respeito da } \\
\text { utilização do óleo residual para fazer } \\
\text { sabão e minimizar os impactos. }\end{array}$ & $45 \begin{array}{l}\text { "Sim, porque a utilização do óleo para fabricação do } \\
\text { sabão, evita o descarte no meio ambiente evitando } \\
\text { de poluir" (participante 10) } \\
\text { "Sim, para reutilizar o óleo reciclando pois faz muito } \\
\text { mal ao meio ambiente." (participante 5) }\end{array}$ \\
\hline $\begin{array}{l}1.3 \text { Estudantes que responderam a a } \\
\text { respeito do que foi aprendido sobre o } \\
\text { descarte inadequado do óleo residual } \\
\text { de fritura. }\end{array}$ & $22 \begin{array}{l}\text { "Sim, que não se deve jogar óleo na pia, pois a } \\
\text { gordura entope e polui." (participante 12) } \\
\text { "Sim, pois evita que jogamos o óleo no meio } \\
\text { ambiente e evitamos a poluição." (participante 15) }\end{array}$ \\
\hline
\end{tabular}

Fonte: do autor (2019)

A última pergunta teve como objetivo a retomada de uma questão do segundo questionário que foi aplicado antes de iniciar a proposta didática, a fim de compará-la e ver se de fato houve alguma mudança na concepção dos alunos após aplicação das aulas teóricas e experimental. De acordo com as respostas analisadas, observou-se uma mudança na concepção dos alunos ao explicar a questão, o qual usaram as propriedades do sabão tais como a polaridade e o caráter tensoativo para explicar quimicamente o que ocorre, porém, alguns alunos não conseguiram mudar sua concepção e responderam igualmente o questionário de sondagem. As respostas foram sistematizadas no Quadro 6.

Quadro 06 - Sistematização das falas dos alunos participantes da pesquisa, com relação ao aprendizado a respeito dos problemas ambientais provocados pelo óleo residual de fritura.

Categoria 2: Por que utilizamos o sabão ou detergente para remover as gorduras das panelas? Expliquem quimicamente o que ocorre?

\begin{tabular}{|l|l|l|}
\hline Subcategoria & $\%$ & Fala dos sujeitos \\
\hline $\begin{array}{l}\text { 2.1 Estudantes que explicaram falando } \\
\text { do sabão das propriedades químicas }\end{array} 67 \begin{array}{l}\text { "O sabão tem propriedades tensoativas. Pois reage } \\
\text { com a água e o óleo. O sabão tem caráter polar e } \\
\text { apolar." (participante 2) } \\
\text { "Porque o sabão tem propriedades tensoativas que } \\
\text { remove a gordura." (participante 10) }\end{array}$ \\
\hline $\begin{array}{l}2.2 \text { Estudantes que associaram a } \\
\text { reação química que ocorre entre o } \\
\text { sabão e a gordura }\end{array}$ & $22 \begin{array}{l}\text { "Devido sua reação química, e sua eficiência na } \\
\text { utilização para remover sujeiras e gorduras." } \\
\text { (participante 5) } \\
\text { "Porque fica mais fácil, devido a propriedade do } \\
\text { sabão faz com que o sabão reage mais fácil na }\end{array}$ \\
\hline
\end{tabular}




\begin{tabular}{|l|c|l|}
\hline & & $\begin{array}{l}\text { remoção das gorduras, pois interage com a água e } \\
\text { com a gordura." (participante 9) }\end{array}$ \\
\hline $\begin{array}{l}2.3 \text { Estudantes que não atenderam } \\
\text { aos objetivos da questão }\end{array}$ & $11 \begin{array}{l}\text { "A maneira que limpa mais os produtos químicos } \\
\text { pode causar impactos com a natureza, se não for } \\
\text { bem utilizado." (participante 7) }\end{array}$ \\
\hline
\end{tabular}

Fonte: do autor (2019)

Diante dos objetivos propostos, o qual teve como finalidade despertar nos alunos da Educação de Jovens e Adultos uma aprendizagem significativa, bem como inserir a Química de forma contextualizada trazendo problemas do cotidiano que os envolvessem tornando-os mais participativos. Foi possível alcançar tais objetivos, de modo que através de cada etapa sistematizada na metodologia, foi sendo observado o comportamento e as mudanças nas concepções dos alunos. O uso da sequência didática envolvendo a experimentação, permitiu um ensino mais dinâmico e interativo, o qual os alunos não se comportaram como meros espectadores, mas interagiram demonstrando curiosidade a respeito do tema abordado. A proposta didática, não teve sucesso com $100 \%$ dos alunos presentes na turma, tal fato ocorre devido a um alto índice de falta de alguns alunos, os quais não participaram de todas as etapas da sequência didática.

\section{CONSIDERAÇÕES FINAIS}

A turma da Educação de Jovens e Adultos a qual foi realizada a proposta didática, mostrou-se bastante diversificada em relação a faixa etária. Porém foi possível perceber que a maioria dos alunos demonstraram interesse pela disciplina de Química apesar das dificuldades de aprendizagem, bem como a falta de recursos utilizados nas aulas.

A partir da inserção da proposta didática na Educação de Jovens e Adultos, foi possível obter bons resultados, os quais apontaram que os estudantes tiveram uma boa aceitação em relação ao tema abordado, contribuindo de forma positiva no processo de ensino-aprendizagem.

Com os resultados analisados desde a primeira etapa da sequência didática, foi possível ver um diferencial no desempenho de vários alunos, os quais se mostraram com uma concepção inicial baseada no seu senso comum e após a evolução das aulas conseguiram apresentar uma concepção mais científica. Desta forma, percebe-se a importância das metodologias didáticas no ensino de Química, as quais atuam na perspectiva de atrair os alunos e os envolverem nas 
aulas, trazendo temas voltados para o seu cotidiano para que assim estes possam ter uma aprendizagem significativa. 


\section{REFERÊNCIAS}

ANDRADE, S. O. et al. Percepção ambiental do corpo docente e discente da modalidade EJA de uma escola estadual no município de Pombal-PB. Revista Verde de Agroecologia e Desenvolvimento Sustentável, 11(1), 22, 2016.

BRASIL. Ministério da Educação e Cultura. Lei de diretrizes e Bases da Educação Nacional, 1996.

BRASIL. Secretaria de Educação Média e Tecnológica (Semtec). Parâmetros Curriculares Nacionais para o Ensino Médio. Brasília: MEC/Semtec, 1999.

BRASIL. Ministério da Educação e Cultura. RESOLUÇÃOCNE/CEB N0 1 de 3 de julho de 2000. Estabelece as Diretrizes Curriculares Nacionais para a Educação de Jovens e Adultos. Brasília, DF, 2000, 68p.

BRASIL. Orientações curriculares para o ensino médio. v. 2. Brasília: MEC; SEB, 2006.

BUDEL, G. J. Ensino de química para a educação de jovens e adultos buscando uma abordagem ciência, tecnologia e sociedade (Master's thesis, Universidade Tecnológica Federal do Paraná), 2016.

DELIZOICOV, D; ANGOTTI, J. A; \& PERMANBUCO, M. M. Ensino de Ciências: fundamentos e métodos. $-5^{\mathrm{a}}$ ed. - São Paulo: Cortez, 2018.

DI PIERRO, M. C. Alfabetização de jovens e adultos no Brasil: lições da prática. Brasília: UNESCO, 2008.

FRANCISCO JR, W. E; FERREIRA, L. H; HARTWIG, D. R. Experimentação problematizadora: fundamentos teóricos e práticos para a aplicação em salas de aula de ciências. Química nova na Escola, 30(4), 34-41, 2008.

FREIRE, P. Pedagogia do oprimido. 48. reimp. São Paulo: Paz e Terra, (2009).

FREITAS, C. F; BARATA, R. A. R; MOREIRA NETO, L. S. Utilização do óleo de cozinha usado como fonte alternativa na produção de energia renovável, buscando reduzir os impactos ambientais. ENEGEP. São Paulo, 2010.

GIL, A. C. Como elaborar projetos de pesquisa. São Paulo: Atlas, Vol. 5, 2010, p. 175.

GUIMARÃES, C. C. Experimentação no ensino de química: caminhos e descaminhos rumo à aprendizagem significativa. Química nova na escola, 31(3), 198-202, 2009.

JARDILINO, J. R. L; DE ARAÚJO, R. M. B. Educação de Jovens e Adultos sujeitos, saberes e práticas. Cortez Editora, 2015. 
LIMA, J. O. G. Perspectivas de novas metodologias no Ensino de Química. Revista espaço acadêmico, 12 (136), 95-101, 2012.

PAZINATO, M. S. et al. Uma abordagem diferenciada para o ensino de funções orgânicas através da temática medicamentos. Química Nova na Escola, 34(1), 21-25, 2012.

PINTO, A. C. O ensino médio de química: o que fazer para melhorá-lo?. Journal of the Brazilian Chemical Society, 23(6), 985-986, 2012.

ROSA, M. F; SILVA, O. S; GALVAN, F. B. Ciência Forense no Ensino de Química por Meio da Experimentação. Química Nova na Escola, 1-9, 2013.

SABESP. Companhia de Saneamento Básico do Estado de São Paulo. Apresenta informações sobre a implantação do programa de reciclagem de óleo de fritura 2019.

SANTOS, J. P. V; RODRIGUES FILHO, G; AMAURO, N. Q. A educação de jovens e adultos e a disciplina de química na visão dos envolvidos. Química Nova na Escola, 38(3), 244-250, 2016.

SOLOMONS, T. W. G; FRYHLE, C. B. Química Orgânica, vol. 1. 12 ed. LTC, 2018.

VELOSO, Y. M. et al. Rotas para reutilização de óleos residuais de fritura. Caderno de Graduação-Ciências Exatas e Tecnológicas-UNIT, 1(1), 1118, 2012.

VIDAL, R. M. B; MELO, R. C. A química dos sentidos-uma proposta metodológica. Química Nova na Escola, 35(1), 182-188, 2013.

WILDNER, L. B. A; HILLIG, C. Reciclagem de óleo comestível e fabricação de sabão como instrumentos de educação ambiental. Revista Eletrônica em Gestão, Educação e Tecnologia Ambiental, 5(5), 813-824, 2012. 